\title{
Clinical Education in COVID-19 Era: A Surgeon's Perspective
}

\section{A. Naren Kumar $^{1} \cdot$ Gaurav Dhoka ${ }^{1}$}

Received: 8 January 2021 / Accepted: 12 April 2021 / Published online: 19 April 2021

(C) Association of Surgeons of India 2021

\section{Dear Editor in Chief,}

The onslaught of coronavirus has been ongoing for 9 months in India. The impact of this pandemic in health services and medical education cannot be overstated. India was one of the earlier and faster countries to adopt and implement e-learning [1]. The recently concluded ASICON is one great example for the same.

However, as educators, are we truly satisfied with the current methods? Do we truly believe that e-learning can be as impactful as projected? Can we work towards a more fruitful method?

In our experience in imparting surgical education to students, we fully understand the need for proper clinical skills. This however is learnt through practice and patience, through patient interaction and prudence. Empathy is learnt by experience, not through disposition.

First and foremost, it is an apparent thing that online attendance for classes is definitely higher than in person attendance, probably because of ease of access [2]. However, we felt that it was difficult to sustain interest among the students for prolonged periods. The students felt there was no "studentteacher bond" in an online platform. The situation worsens in the event of a clinical class, as most teaching methods dissolve into showing demonstration videos.

Though theory classes are overall accepted on both sides, through innovative methods like "flipped learning" or "blended learning" methodology, clinical classes are a totally new ball game [3,4]. We propose that newer more personal methods of clinical teaching can be considered as follows.

Having a direct patient to student interaction, either via

\section{A. Naren Kumar}

thundervibe@gmail.com; surgicalcare.naren@gmail.com

Gaurav Dhoka

gaurav.dhoka@ymail.com

1 Department of General Surgery, Shri Sathya Sai Medical College and Research Institute, Sri Balaji Vidyapeeth (Deemed to be University), Tiruporur-Guduvancherry Main Road, Ammapettai, ChengalpetTaluk, Kancheepuram District, Nellikuppam, Tamil Nadu 603108, India video conferencing or conference telecall, will facilitate students to develop the much-desired communication skills. Though widespread "virtual reality" is a farfetched notion still in India, the facilitator of the session could wear POV cameras while examining a patient to provide a "virtual 1st person view" for the students viewing the class. This, we feel, would create a more direct and visual enrichment for the students.

We also propose the introduction of open book examinations, in which students will be given a specific topic to prepare the previous day, and an online Viva can be done. This will remove the hesitancy on the student's side, alleviate their fear of being wrong, and promote more interpersonal communication, which is the biggest drawback of e-learning.

Another aspect of e-learning, we propose is that of "student reels" where we pick some students to role play with friends and family to enact a clinical situation. This will facilitate in developing empathy, which we feel is an important attribute in clinical learning.

To conclude, though this pandemic has been devastating to say the least, it definitely has sharpened our views in diversifying medical education to a more varied and evolving concept. We should take this as an opportunity to strengthen what we have learnt and not fall back to our old ways. We should learn to not react out of urgency but act out of preparedness and intent.

\section{References}

1. Mathivanan SK, Jayagopal P, Ahmed S et al (2021) Adoption of elearning during lockdown in India. Int J Syst Assur Eng Manag. https://doi.org/10.1007/s13198-021-01072-4

2. Karabulut-Ilgu A, Cherrez NJ, Jahren CT (2018) A systematic review of research on the flipped learning method in engineering education. Br J Educ Technol 49(3):398-411

3. Verma A, Verma S, Garg P, Godara R (2020) Online teaching during COVID-19: perception of medical undergraduate students. Indian J Surg 82:299-300

4. Ruiz JG, Mintzer MJ, Leipzig RM (2006) The impact of e-learning in medical education. Acad Med 81:207-212

Publisher's Note Springer Nature remains neutral with regard to jurisdictional claims in published maps and institutional affiliations. 